\title{
Biosecurity must be internationally supervised
}

\section{US restrictions on cooperation are hampering legitimate microbiological research.}

Sir - In his Commentary article "Isolation is not the answer" (Nature 429, 603; 2004), Thomas May warns that US regulations on bioterror-related research in the United States may lead to scientific isolationism.

We can confirm that national regulations do affect scientists in other countries. A survey we conducted recently in Germany revealed that US regulations are having an adverse impact on German microbiological research.

In spring 2004, we sent questionnaires to all German academic medical and veterinary institutions that are, according to their websites, working in the area of microbiology. From a total of 67 respondents (response rate 33\%), 47 commented on changes in cooperation with US partners. Of these, 21 stated that access to US culture collections or microorganisms had become "worse" (11 respondents) or "much worse" (10 respondents) since 11 September 2001. This unfavourable development has had a direct negative effect on microbiological research in Germany: 13 respondents stated that there had been measurable impacts, such as delays in some research projects, the need to switch to different organisms or technologies, or the need to cooperate with other partners. Two microbiologists reported that projects had to be stopped, or could not begin, because of reduced cooperation with US partners.

A certain response bias cannot be ruled out. Researchers affected by US regulations are more likely to have responded to the questionnaire than those not working with pathogens or not cooperating with international partners.
The responses nevertheless indicate that failure to harmonize international biosecurity and biosafety measures may well hamper legitimate scientific research outside US borders.

Enhanced supervision of microbiology and related research is much needed, but it should follow internationally agreed rules (see J. D. Steinbruner and E. D. Harris Issues Sci. Technol. 47-54; Spring 2003). As the US National Research Council and the UK Royal Society have suggested, harmonized international supervision would be better suited to accommodate both scientific and security concerns.

Jan van Aken, Stefan Johannsen, Regine Kollek

University of Hamburg, Falkenried 94, D-20251 Hamburg, Germany

\section{Linnean Society backs Godfray on use of web}

Sir - Your Editorial "Ignorance is not bliss" (Nature 430, 385; 2004) notes that Charles Godfray "argues that taxonomy must emerge from museums to become a web-based information science". It continues: "Some initiatives of this ilk are under way, but the call has been short-sightedly rejected by much of the taxonomic community, notably the Linnean Society of London."

I was president of the Linnean Society from 2000 to 2003. During this period the society submitted written evidence to the Inquiry into Systematic Biology and Biodiversity held by the House of Lords Select Committee on Science and Technology. This evidence was published in What on Earth? The Threat to the Science Underpinning Conservation: Evidence (HL paper 118 (ii); 2002).

On pages 124-125, the following statement occurs as part of the Linnean Society's evidence (all of which was formally approved by its council): "Professor Charles Godfray FRS ... argues powerfully and persuasively for a major sea-change in taxonomy whereby the systematics of all groups of organisms would become a single webbased resource .... His proposal would have the particular advantage that at last, taxonomic information would become easily available .... . This will be essential if real and effective progress is to be made in the conservation of biodiversity in the UK."

The Linnean Society therefore does not reject but supports the initiatives that have been proposed by Charles Godfray. David Smith

13 Abbotsford Park, Edinburgh EH10 5DZ, UK

\section{Need for economists to set global priorities}

Sir - In May, the Copenhagen Consensus (www.copenhagenconsensus.com) brought 38 of the world's top economists to Denmark to make a prioritized list of solutions to global challenges. In his critical judgement of the consensus, "Seeking a global solution" (Nature 430, 725-726; 2004), Jeffrey Sachs misunderstood the project in three fundamental ways.

First, Sachs asserted that, because the world has promised to spend much more than the US $\$ 50$ billion discussed by the Copenhagen Consensus, prioritization is unnecessary. But more or less money would not alter the project's outcome. If more than $\$ 50$ billion were marshalled, the consensus list would simply show where the extra money should be directed.

The claim that the developed world has promised to substantially increase development assistance should be treated with caution: since 1970 the United Nations has wanted such spending to double as a percentage of GNP, but it has fallen substantially since then (see www. worldhunger.org/articles/global/ Intconforaid/develfinance.htm). It seems unrealistic to assume that the resources allocated will be so large that we will not have to prioritize. The $\$ 50$ billion was chosen as an example of a realistic commitment to additional spending.

Second, Sachs' criticism that the Copenhagen Consensus consisted solely of economists missed the very point of the project. Economists have expertise in economic prioritization. It is they and not climatologists or malaria experts who can prioritize between battling global warming or communicable disease. Of course, all economic estimates are based squarely on the best natural-science models.

Third, in discussing why efforts to handle climate change ended up at the bottom of the Copenhagen Consensus list, Sachs left the distorted impression that all climate economists believed the relatively high carbon-tax proposal should have been given a higher priority. In fact, two of the three climate economists explicitly found the costs exceeded the benefits. The expert panel endorsed this view.

The Copenhagen Consensus was the first project to prioritize the major challenges facing the world. Morally we must focus on the best priorities first, or we do less good for humanity. Prioritization means not everything is done first. This often makes good people fret because 'we should do everything, although we do not and cannot.

That a prominent economist such as Sachs should posit such flawed arguments underlines the case both for the Copenhagen Consensus and for a continued public discourse on prioritization. Bjørn Lomborg Copenhagen Consensus, Linnesgade 18, DK-1361 Copenhagen K, Denmark 